\title{
Optically Stimulated Luminescence in Tm-Doped Calcium Fluoride Phosphor Crystal for Application to a Novel Passive Type Dosimeter
}

\author{
Hidehito Nanto*, Ryota Nakagawa, Takayuki Yanagida ${ }^{1}$, Yutaka Fujimoto², \\ Kentaro Fukuda ${ }^{3}$, Yuka Miyamoto ${ }^{4}$, Kazuki Hirasawa and Yoshinori Takei \\ Advanced Materials Science R\&D Center, Kanazawa Institute of Technology, \\ 3-1 Yatsukaho, Hakusan 924-0838, Japan \\ 'Graduate School of Materials Science, Nara Institute of Science and Technology, \\ 8916-5 Takayama, Ikoma, Nara 630-0192, Japan \\ ${ }^{2}$ Department of Applied Chemistry, Tohoku University, \\ 6-6-07 Aoba, Aramaki, Sendai 980-8579, Japan \\ ${ }^{3}$ Tokuyama Corporation, 1-1 Mikage-cho, Shunan-shi, Yamaguchi 745-8648, Japan \\ ${ }^{4}$ Oarai Research Center, Chiyoda Techno Co. Ltd., \\ 3681 Narita-Cho, Oarai-machi, Ibaraki 311-1313, Japan
}

(Received October 12, 2014; accepted January 23, 2015)

Key words: optically stimulated luminescence, passive type dosimeter, calcium fluoride, thermally stimulated luminescence, thulium

An intense optically stimulated luminescence (OSL) with four emission bands in the wavelength range from 290 to $420 \mathrm{~nm}$ is observed for the first time in X-ray-irradiated Tm-doped $\mathrm{CaF}_{2}\left(\mathrm{CaF}_{2}: \mathrm{Tm}\right)$ phosphor crystal. The OSL intensity increases almost linearly with increasing X-ray absorbed dose. Thermally stimulated luminescence (TSL) glow curves with four peaks are also observed in X-ray-irradiated $\mathrm{CaF}_{2}: \mathrm{Tm}$ phosphor crystal. It is confirmed that the shape of the TSL glow curve in X-ray-irradiated $\mathrm{CaF}_{2}: \mathrm{Tm}$ phosphor crystal is the same as that of a commercially available dosimeter (TLD-300). An OSL emission and stimulation mechanism of X-ray-irradiated $\mathrm{CaF}_{2}: \mathrm{Tm}$ phosphor crystal is proposed.

\section{Introduction}

Similarly to the thermally stimulated luminescence (TSL) phenomenon, which is used for personal and environmental radiation dosimetry, the optically stimulated luminescence (OSL) phenomenon is based on the electron and/or hole traps and luminescence centers in storage phosphor materials. The ionizing radiation creates free electrons and holes that are trapped at the crystal lattice site or impurities in the phosphor

*Corresponding author: e-mail: hnanto@neptune.kanazawa-it.ac.jp 
materials. Detrapping of these electrons and holes requires energy, which, in the TSL process, is provided by heating the phosphor materials. In the OSL process, photons are absorbed from the stimulating light during detrapping transition and the free carriers created as a result recombine with luminescence centers, whereby photons from visible to infrared wavelengths are emitted. Since the density of trapped electrons and/or holes, that is, OSL intensity, is in most cases proportional to the dose of ionizing radiation, the storage phosphor materials with OSL can be used as a novel passive sensor for ionizing radiation for personal and environmental radiation monitoring.

Up to now, OSL materials, such as C-doped $\mathrm{Al}_{2} \mathrm{O}_{3}^{(1,2)}$ for personal, environmental, medical, and space dosimetry applications, $\mathrm{BeO}^{(3-5)}$ for personal dosimetry, Tb-doped $\mathrm{MgO}^{(6)}$ for personal dosimetry, Cu-doped $\mathrm{SiO}_{2}$ (quartz crystal) ${ }^{(7,8)}$ for optical fiber dosimetry, Sm:Ce-codoped $X \mathrm{~S}(X=\mathrm{Mg}, \mathrm{Ca}, \mathrm{Sr})^{(9-11)}$ for optical fiber dosimetry, Cedoped $\mathrm{CaF}_{2}{ }^{(12)}$ for personal dosimetry, Eu-doped $\mathrm{BaF} X(X=\mathrm{Br}, \mathrm{Cl}, \mathrm{I}),{ }^{(13-15)} \mathrm{RbBr},{ }^{(16)}$ $\mathrm{CsBr},{ }^{(17)}$ and $\mathrm{K} X(X=\mathrm{Br}, \mathrm{Cl})^{(18-20)}$ for personal dosimetry and two-dimensional $\mathrm{X}$-ray imaging, and Sn-doped borate and phosphate glass for personal dosimetry, ${ }^{(21)}$ have been investigated for a long time. Consequently, personal dosimeters using C-doped $\mathrm{Al}_{2} \mathrm{O}_{3}$ and $\mathrm{BeO}$ storage phosphors as well as two-dimensional $\mathrm{X}$-ray imaging sensors using Eudoped $\mathrm{BaF} X$, Eu-doped $\mathrm{CsBr}$ for computed radiography are now commercially available. However, many problems must be solved, such as low OSL intensity in C-doped $\mathrm{Al}_{2} \mathrm{O}_{3}$ and $\mathrm{BeO}$ storage phosphors and degradation of OSL properties due to deliquescency in alkali halide phosphors.

By surveying possible phosphor materials, especially fluoride and glass phosphor materials, we found that Tm-doped $\mathrm{CaF}_{2}\left(\mathrm{CaF}_{2}: \mathrm{Tm}\right)$ exhibits an efficient OSL and fairly good dosimetric properties. In this paper, the OSL characteristics in X-ray-irradiated $\mathrm{CaF}_{2}: \mathrm{Tm}$ phosphor crystals are reported for the first time.

\section{Experimental Procedure}

$\mathrm{Tm}^{3+}$-doped $\mathrm{CaF}_{2}$ phosphor samples were fabricated using the conventional solidification method developed by Tokuyama Corporation. ${ }^{(22)}$ Starting materials were prepared from the stoichiometric mixture of $99.9 \%$ pure $\mathrm{CaF}_{2}$ and $\mathrm{TmF}_{3}$ powders produced by Stella Chemifa Corporation. The $\mathrm{Tm}^{3+}$ concentration was varied from 0.1 to $10 \mathrm{~mol} \%$. The powder mixtures placed in a carbon crucible in a stainless steel chamber with a carbon resister were heated at $400{ }^{\circ} \mathrm{C}$ for $8 \mathrm{~h}$ in vacuum at around $10^{-2} \mathrm{~Pa}$ in order to remove trace oxygen. After baking at $400{ }^{\circ} \mathrm{C}$ in vacuum, the chamber was filled with high-purity $\mathrm{Ar}$ gas $(5 \mathrm{~N})$ and $\mathrm{CF}_{4}$ gas $(5 \mathrm{~N})$ to restore ambient pressure. The crucible was then annealed up to the melting point of $\mathrm{CaF}_{2}$, about $1430{ }^{\circ} \mathrm{C}$, for $30 \mathrm{~min}$. Prepared $\mathrm{CaF}_{2}$ crystals were polished and then cut into $1 \times 2 \times 5 \mathrm{~mm}^{3}$ pieces to measure luminescence properties such as PL, OSL, and TSL.

Optical properties such as PL and OSL were measured using a Hitachi F-4500 fluorescence spectrometer and optical absorption spectra using a Hitachi spectrophotometer (U-2000). X-ray irradiation was carried out using an X-ray tube with a Mo target operated at $60 \mathrm{kV}$ and $35 \mathrm{~mA}$. 


\section{Results and Discussion}

The $\mathrm{CaF}_{2}: \mathrm{Tm}(0.1 \mathrm{~mol} \%)$ phosphor sample without X-ray irradiation exhibits an efficient PL peak in the wavelength range from 290 to $420 \mathrm{~nm}$. Figure 1 shows typical PL emission and excitation spectra. It can be seen from the figure that there are four emission bands at about 298, 340, and $350 \mathrm{~nm}$, which correspond to internal $\mathrm{Tm}$ transitions. ${ }^{(23)}$ These PL emission bands were observed when the $\mathrm{CaF}_{2}: \mathrm{Tm}$ phosphor sample was excited with 220 and $240 \mathrm{~nm}$ light.

An intense OSL with several peaks in the wavelength range from 280 to $430 \mathrm{~nm}$ was observed when an X-ray-irradiated $\mathrm{CaF}_{2}: \mathrm{Tm}$ phosphor sample was stimulated with about 500 and $600 \mathrm{~nm}$ light. Typical OSL emission and stimulation spectra are shown in Fig. 2. The OSL emission bands that coincide with the PL emission bands are assigned to inner ionic transitions of isolated $\mathrm{Tm}^{3+}$ ions occupying at cation (calcium ion) sites.

Figure 3 shows the dependence of the OSL spectra on X-ray irradiation dose in the absorbed dose range from 0.001 to $0.1 \mathrm{~Gy}$. The OSL spectra as a function of X-ray absorbed dose in a high absorbed dose range from 1 to 10 Gy are shown in Fig. 4. It was found that the OSL intensity increases with increasing X-ray absorbed dose, as shown in Fig. 5. This result strongly suggests that the $\mathrm{CaF}_{2}: \mathrm{Tm}$ phosphors can be used as the storage phosphor materials of the passive OSL dosimeter that can be applied to personal and environmental monitoring as well as computed radiography.

An intense TSL was also observed in the X-ray-irradiated $\mathrm{CaF}_{2}$ : $\mathrm{Tm}$ phosphor sample. Typical TSL glow curves of an X-ray-irradiated sample in a fairy low absorbed dose range from 0.0005 to 0.001 Gy are shown in Fig. 6. The TSL glow curves of an X-rayirradiated phosphor sample in the absorbed dose range from 0.01 to 0.1 Gy are also shown in Fig. 7. It was found that the TSL intensity increases with X-ray absorbed dose, as shown in Fig. 8. The personal dosimeter using the TSL in $\mathrm{CaF}_{2}: \mathrm{Tm}$ was first introduced in $1977^{(24)}$ and sold by Bicron-NE (Harshow) as TLD-300. The TSL glow curve
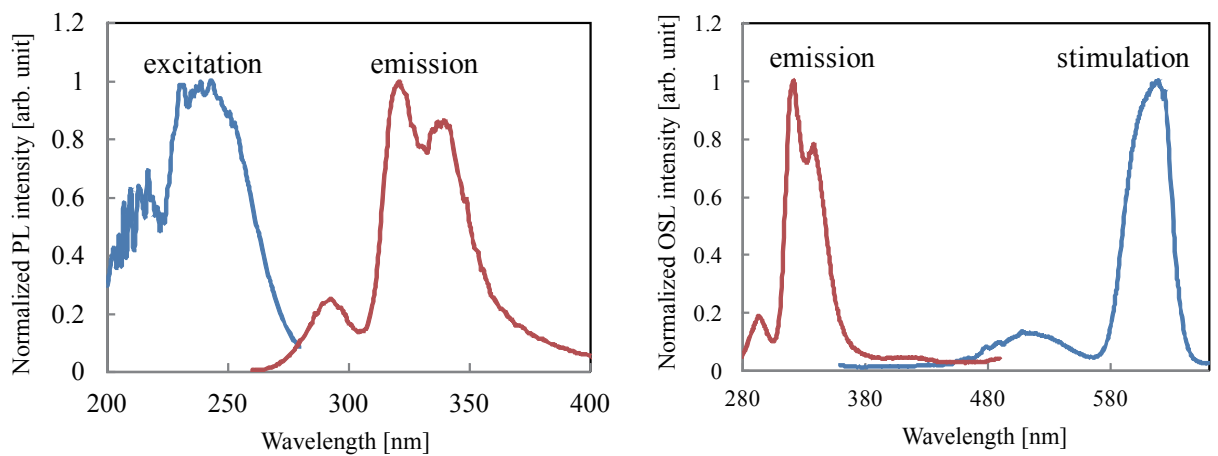

Fig. 1 (left). (Color online) Typical PL emission and excitation spectra of $\mathrm{CaF}_{2}: \mathrm{Tm}$ phosphor sample without X-ray irradiation.

Fig. 2 (right). (Color online) Typical OSL emission and stimulation spectra of X-ray-irradiated $\mathrm{CaF}_{2}: \mathrm{Tm}$ phosphor sample. 

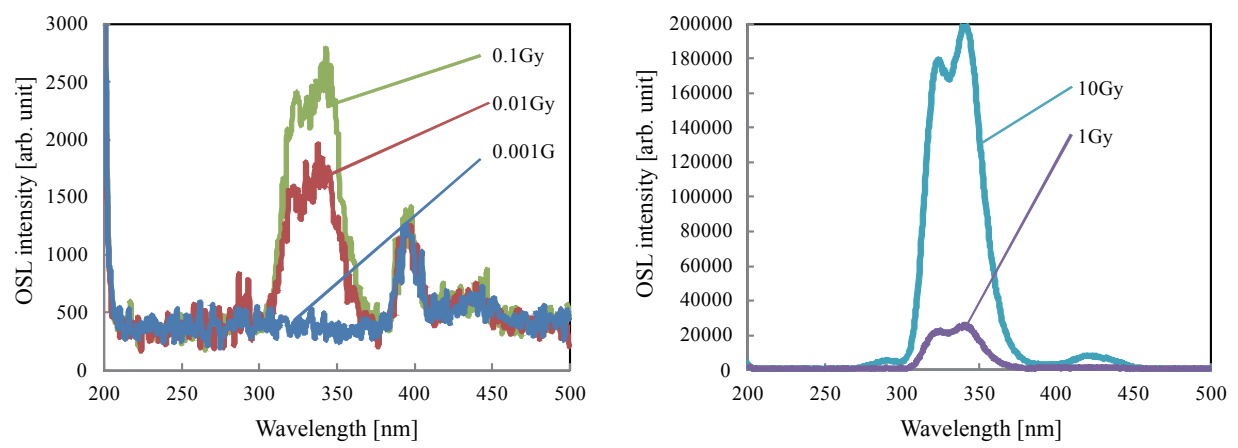

Fig. 3 (left). (Color online) Dependence of the OSL spectra on X-ray absorbed dose in the absorbed dose range from 0.001 to $0.1 \mathrm{~Gy}$.

Fig. 4 (right). (Color online) Dependence of the OSL spectra on X-ray absorbed dose in the absorbed dose range from from 1 to $10 \mathrm{~Gy}$.
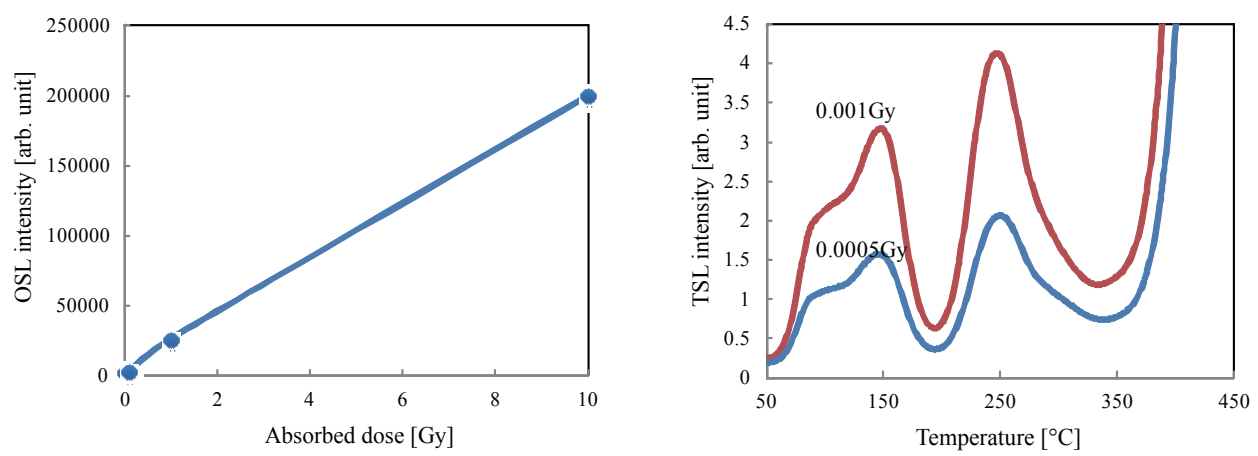

Fig. 5 (left). (Color online) OSL intensity of an X-ray-irradiated $\mathrm{CaF}_{2}: \mathrm{Tm}$ phosphor sample as a function of absorbed dose.

Fig. 6 (right). (Color online) Typical TSL glow curves of an X-ray-irradiated sample in low absorbed dose range from 0.0005 to $0.001 \mathrm{~Gy}$.
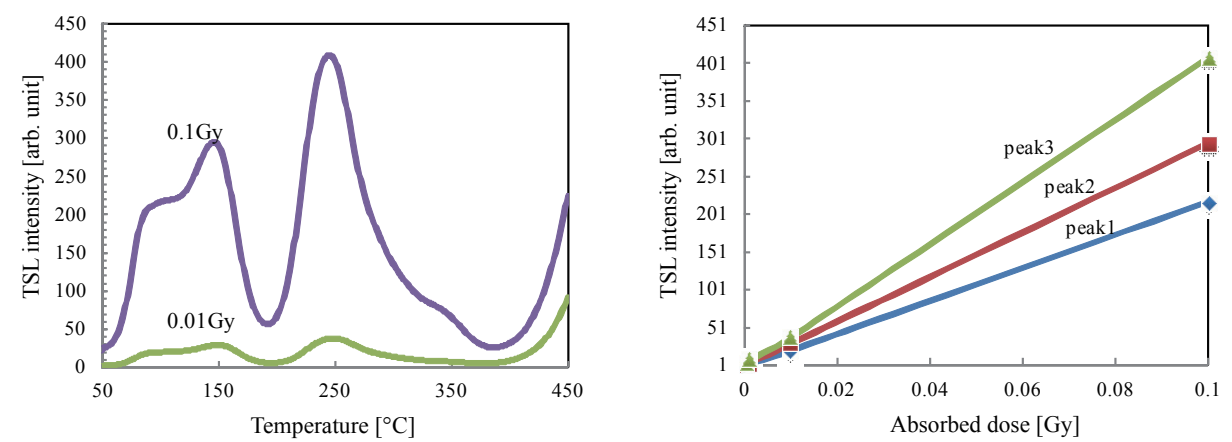

Fig. 7 (left). (Color online) TSL glow curves of an X-ray-irradiated phosphor sample in the absorbed dose range from 0.01 to $0.1 \mathrm{~Gy}$.

Fig. 8 (right). (Color online) Intensities of TSL peaks, such as 70 (peak 1), 150 (peak 2), and 250 ${ }^{\circ} \mathrm{C}$ (peak 3 ) as a function of absorbed dose, in X-ray-irradiated $\mathrm{CaF}_{2}: \mathrm{Tm}$ phosphor sample. 
of the TLD-300 consists of several well known separated peaks in the temperature range from 100 to $300{ }^{\circ} \mathrm{C}$. It was confirmed that the TSL glow peaks at about $70,150,250$, and $300{ }^{\circ} \mathrm{C}$ in our phosphor sample almost coincide with those of commercially available TLD300. ${ }^{(22)}$ Kafadar et al. ${ }^{(23)}$ have reported that these TSL peaks obey first-order kinetics, that is, the electrons stimulated from traps recombine with the hole traps without retrapping. Therefore, the following OSL emission and stimulation mechanism can be proposed. Free electrons and holes created by X-ray irradiation are trapped at anion (florin) vacancies to produce color centers such as $\mathrm{F}$ and $\mathrm{F}_{2}$ centers, and at $\mathrm{Tm}^{3+}$ ions to produce $\mathrm{Tm}^{4+}$ ions, respectively. By subsequent stimulation with about 500 and $600 \mathrm{~nm}$ light, electrons, which are optically released from electron traps such as anion vacancies, recombine with the holes trapped at the $\mathrm{Tm}^{4+}$ ions leading to excited $\mathrm{Tm}^{3+}$ ions from which the OSL is emitted, in accordance with the following reactions:

$$
\mathrm{Tm}^{4+}+\mathrm{e}^{-} \rightarrow\left(\mathrm{Tm}^{3+}\right)^{*} \rightarrow \mathrm{Tm}^{3+}+\text { OSL emission }
$$

where $\left(\mathrm{Tm}^{3+}\right)^{*}$ is the trivalent thulium excited state and $\mathrm{e}^{-}$is the free electron created by optical stimulation from electron traps. In this process, all electrons stimulated from electron traps to the conduction band recombine with holes at $\mathrm{Tm}^{4+}$ ions without retrapping, because the TSL peaks obey first-order kinetics.

It was confirmed that 1 and $10 \mathrm{~mol} \% \mathrm{Tm}$-doped $\mathrm{CaF}_{2}$ phosphor samples exhibited low OSL intensities. Thus, the Tm doping concentration should be optimized in a future study.

\section{Conclusions}

An intense OSL in the wavelength range from 280 to $380 \mathrm{~nm}$ is observed, for the first time, by stimulating X-ray-irradiated $\mathrm{CaF}_{2}: \mathrm{Tm}$ phosphors with 500 and $600 \mathrm{~nm}$ light; such an intense OSL corresponds to the energy that flows from electron traps due to anion vacancies to the conduction band. The OSL intensity increases with the X-ray absorbed dose in the range from 0.001 to $10 \mathrm{~Gy}$, indicating that the OSL phenomenon in $\mathrm{CaF}_{2}: \mathrm{Tm}$ storage phosphors can be useful in developing a novel storage phosphor material for solid-state passive dosimeters for personal and environmental radiation monitoring. An OSL stimulation and emission mechanism is also proposed.

\section{Acknowledgements}

The authors wish to thank Mr. A. Michii, H. Igarashi, and K. Hashimoto for their excellent assistance in the experiments. This work was partly supported by the fund of Japan Science and Technology Agency (JST). This work was also partially supported by the SPRITS program, Kyoto University and the Cooperative Research Project of Research Institute of Electronics, Shizuoka University. This study is partially supported by the Cooperative Research Project of Research Institute of Electronics, Shizuoka University. 


\section{References}

1 M. S. Akselrod and S. W. S. McKeever: Radiat. Prot. Dosim. 81 (1999) 167.

2 S. W. S. McKeever and M. S. Akselrod: Radiat. Prot. Dosim. 84 (1999) 317.

3 M. Sommer and J. Henniger: Radiat. Prot. Dosim. 119 (2006) 394.

4 M. Sommer, R. Freudenberg and J. Henniger: Radiat. Meas. 42 (2007) 617.

5 M. Sommer, A. Jahn and J. Henniger: Radiat. Meas. 43 (2008) 353.

6 A. J. J. Bos, M. Prokic and J. C. Brouwer: Radiat. Prot. Dosim. 119 (2006)130.

7 B. L. Justus, C. D. Merritt, K. J. Pawlovich, A. L. Huston and S. Rychnovisky: Radiat. Prot. Dosim. 84 (1999) 189.

8 B. L. Justus, K. J. Pawlovich, C. D. Merritt and A. L. Huston: Radiat. Prot. Dosim. 81 (1999) 5.

9 L. Dusseau, D. Plattard, J. R. Vaille, G. Polge, G. Ranchoux, F. Saigne, J. Fesquet and J. Gasoit: IEEE Trans. Nucl. Sci. 47 (2000) 2412.

10 D. Lapraz, H. Prevost and K. Idri: Phys. Status. Solidi A 203 (2006) 3793.

11 F. Ravotti, D. Benoit, P. Lefebvre, P. Valvin, J. R. Vaille, L. Dusseau, J. Fesquet and J. Gasiot: J. Appl. Phys. 102 (2007) 123102.

12 T. Yanagida, Y. Fujimoto, K. Watanabe, K. Fukuda, N. Kawaguchi, Y. Miyamoto and H. Nanto: Radia. Meas. (2014) (in press).

13 M. Sonoda, M. Takano, J. Miyahara and H. Kato: Radiology 148 (1983) 833.

14 H. von Seggern: Braz. J. Phys. 29 (1999) 254.

15 J. A. Rowlands: Phys. Med. Biol. 47 (2002) R123.

16 K. Amitani, A. Kano, H. Tsuchiya and F. Shimada: Adv. Printing of Paper Summaries, 26th Fall Symp., SPSE (1986) 180.

17 H. Nanto, Y. Takei, A. Nishimura, Y. Nakano, T. Shouji, T. Yanagita and S. Kasai: Proc. SPIE (Medical Imaging 2006: Physics of Medical Imaging) 6142 (2006) 61422W-1.

18 H. Nanto, K. Murayama, T. Usuda, S. Taniguchi and N. Takeuchi: Radia. Prot. Dosim. 47 (1993) 281.

19 H. Nanto, Y. Douguchi, M. Kadota, J. Nishishita, M. Ikeda, T. Shinkawa, N. Kashiwagi and S. Nasu: Trans. IEE Jpn. 117-E (1997) 142.

20 Y. Douguchi, H. Nanto, T. Sato, A. Imai, S. Nasu, E. Kusano and A. Kinbara: Radiat. Prot. Dosim. 84 (1999) 143.

21 H. Nanto, R. Nakagawa, Y. Takei, K. Hirasawa, Y. Miyamoto, M. Masai, T. Kurobori, T. Yanagida and Y. Fujimoto: Nuc. Instr. \& Methods (Proc. SORMA 2014) (2015) (in press).

22 N. Kawaguchi, T. Yanagida, Y. Futami, Y. Fujimoto, K. Fukuda, S. Kajimoto, H. Fukumura, S. Kurosawa, Y. Yokota and A. Yoshikawa: Opt. Mater. 35 (2013) 1898.

23 V. E. Kafadar, M. Bedir, A. N. Yazici and T. Gunal: Chin. Phys. Lett. 30 (2013) 057802.

24 A. Lucas and B. Kapsar: Proc. 5th Int. Conf. Lumin. Dosim. (1977) p.131. 